\title{
Factors Associated with Compliance among Methadone Maintenance Treatment Transfers: Evidence from Audit Records at Clinics in Guangdong, China
}

\author{
Cheng Gong ${ }^{\dagger}$, Xia Zou ${ }^{\dagger}$, Wen Chen, Yin Liu, Qian Lu and Li Ling * \\ Department of Medical Statistics, School of Public Health, Sun Yat-sen University, Guangzhou 510080, China; \\ gongch25@mail2.sysu.edu.cn (C.G.); zouxia@mail3.sysu.edu.cn (X.Z.); chenw43@mail.sysu.edu.cn (W.C.); \\ liuy429@mail2.sysu.edu.cn (Y.L.); luqian7@mail2.sysu.edu.cn (Q.L.) \\ * Correspondence: lingli@mail.sysu.edu.cn; Tel.: +86-020-873-3319 \\ + These authors contributed equally to this work.
}

Received: 4 April 2019; Accepted: 3 June 2019; Published: 6 June 2019

\begin{abstract}
Methadone maintenance treatment (MMT) requires patients to intake their daily dose in person at their clinic. Therefore, transfer services are vital for patients who need temporary leave from their primary MMT clinic. However, studies have shown that transfer patients might delay return after temporary leave, leading to missed doses and putting them at risk of increased harm. In this study, we aimed to explore the transfer rates and factors associated with MMT patients who delayed return during a transfer period. In this retrospective analysis, we used audit records from the web-based management system from six MMT clinics in Guangdong, China. Multilevel logistic regression and multilevel Poisson regression analyses were used to examine the factors associated with patients who delayed return to their primary MMT clinic. A total of 459 people used the transfer system 2940 times between January 2006 and December 2016. Of those, patients delayed return to their primary MMT clinic 1199 times (40.78\%). Patients who transferred regularly had poor compliance rates with MMT treatment. Those who once dropped out from and then re-enrolled in MMT were more likely to delay return. Most patients (82.71\%) who used the transfer service for "work" were more likely to prolong their delay length. The findings highlight that a more flexible transfer system would minimize inconvenience to the patients.
\end{abstract}

Keywords: methadone maintenance treatment; opioid dependence; transfer; service; delayed treatment

\section{Introduction}

Opioid dependence is a chronic health condition that necessitates long-term treatment [1,2]. Methadone maintenance treatment (MMT) is regarded by the Word Health Organization (WHO, 2009) as the most effective substitute therapy for opioid addiction. According to the pharmacological action of methadone, daily treatment is needed to minimize a user's withdrawal symptoms [3].

With long-term treatment, the social functioning of MMT patients improves greatly [4]. With the increase in social activities such as work and travel, patients' demands for temporary leave gradually increase [5,6]. In response, take-home doses and transfer services are the most prevalent solutions worldwide. For example, in Singapore, MMT clinics provide take-home doses for the patients who are unable to attend the clinic every day [7]. However, the take-home doses are not available for all patients in the clinic [8]. Take-home doses are a privilege and are only provided to those patients who (1) have fully cooperated with the treatment, and (2) have a minimum of three months with no positive 
urine drug test [8]. Additionally, empirical evidence has shown that take-home doses, without strict medical supervision, could increase the risk of misuse and diversion, such as methadone injection and methadone being sold out under the black market [9-12].

Different from take-home doses, some countries, such as Australia, Myanmar, and China, provide transfer services to patients who need temporarily leave from their primary clinic. As a fundamental aspect of care, transfer services allow transfer patients to continue their treatment at another MMT facility near their destination [13-16]. The transfer patients are able to take their doses under medical supervision without the potential risk of misuse and diversion. When the patients need to use the transfer service, they are required to report their duration of leave, destination, and reason for transfer request in their transfer form for each transfer request $[13,17,18]$ so that the administration can arrange the transfer with their treatment history, including the details of treatment date and dose $[18,19]$. This transfer form is delivered from the primary clinic to the receiving clinic through manual submission or an internet management system. China has the world's largest methadone service system [20]. The transfer service system has been running more than 10 years in China. When the patients need to take a temporary leave of absence from their primary registered MMT clinics, they can theoretically continue their treatment at another MMT facility near their destination [16]. Transfers are arranged in advance to avoid interrupted treatment and minimize inconvenience to the patients.

A previous study showed that patients who use the transfer service commonly delay return to their primary MMT clinic after temporary leave [21]. Delayed return is identified as when the patient returns later than the date declared in a patient's transfer application to their primary MMT clinic. About half of MMT patients who transfer delay their return to their primary MMT clinic by three days on average [21,22]. When patients delay their return to their primary MMT clinic, they miss doses and might be at increased risk of withdrawal symptoms, drug relapsing, and spreading infectious diseases [23-26]. However, to the best of our knowledge, no study has ever assessed association between transfer service and patients' delayed return.

To fill this gap, we first examined the participant transfer rates. Second, we explored the factors associated with patients who are likely to delay their return to their primary MMT clinic.

\section{Materials and Methods}

\subsection{Study Site and Sampling}

In Guangdong province, South China, there were 457,000 registered drug addicts in 2017, accounting for $17.9 \%$ of China's total 2,553,000 reported drug addicts [27]. Due to the large number of registered drug users in Guangdong province, 66 MMT clinics were open at the end of 2016 [28]. Since 2008, all the clinics have provided transfer services. In this retrospective analysis, we invited all 66 MMT clinics in Guangdong to participate in this study. Six clinics in four cities across Guangdong province: Guangzhou, Dongguan, Jiangmen, and Yangjiang with full audit records all located in the Pearl River Delta agreed to join our study. The six clinics all opened in 2006, treating approximately 100 patients per day, and provided the same methadone maintenance treatment.

Patients who successfully used the MMT transfer service in the six MMT clinics from 1 January 2006 to 31 December 2016 were included in our study. Successful use of the MMT transfer service was defined as the patient having records about the transfer application and medical records after returning to their primary MMT clinic. We excluded (1) patients whose primary clinic was not one of the six sites included in this study and (2) patient dropouts, defined as those who missed 14 continuous days of treatment.

\subsection{Data Collection}

The Chinese National MMT Data Management System was established simultaneously with the opening of the first eight MMT clinics in China in 2004 across the provinces of Sichuan, Yunnan, Guizhou, Zhejiang, and Guangxi [11]. For medical supervision needs, each patient registered in a 
MMT clinic must have a unique number to access treatment. Each MMT clinic updates their service records according to the patient's daily treatment. All daily treatment records were collected from the web-based Chinese National MMT Data Management System from the six clinics. We extracted eligible records between 1 January 2006 and 31 December 2016. The information in the records included: (1) characteristics of MMT patients (age, sex, education, and employment status); (b) methadone treatment-related information (start date of methadone maintenance treatment, number of times enrolled in MMT, the date of methadone intake, and dosage); (c) drug use history (age of initiated drug use, intravenous drug use, and the results of urine drug tests); and (d) transfer service records (the frequency of transfers, the start date of each transfer, the declared return date, and the actual return date of the patient, methadone intake and dosage during transfer, and the reason for transfer). All the records were collected and de-identified before analysis.

\subsection{Study Variables}

Dependent variables included delayed return (yes/no) and the length of delay. Delayed return was defined as the patient returning later than the date declared in their transfer to their primary registered MMT clinic. The length of delay (days) was the duration between the declared date of return in the patient's application form and the actual date of return.

Our main independent variables were the characteristics of each transfer: (1) the frequency of transfer service use (times/year); (2) the duration of each transfer to other MMT clinics, which was defined as the duration from the date the transfer started to the declared return date in the patient's application form; (3) the duration of MMT before transfer, which was calculated by the transfer start date minus the first MMT-enrollment date (year); (4) the average daily methadone dosage (mg/day) during the transfer period; (5) the reason for transfer (work, travel, medical, or other); (6) the compliance rate during the transfer period, which was calculated as the number of days of methadone intake over the number of applied transfer days; and (7) the result of urine drug tests in the past three months before transfer (\%). We also included demographic characteristics (age, sex, employment status, and education level), methadone treatment-related characteristics (MMT dropout and re-enrollment rates, the duration of MMT before transfer), and drug use history (the results of urine drug tests in the past three months before transfer) as probable confounders in this study.

\subsection{Statistical Analysis}

We used mean and standard deviation (SD) to describe normally distributed continuous variables. The median and interquartile range (IQR) were used to describe non-normally distributed continuous variables. The hierarchical structure of the data resulted in the clustering of transfers (level 1) among different patients (level 2). A two-level hierarchical logistic regression analysis was used to explore the risk factors of delayed return (Model A). The odds ratio (OR) and adjusted odds ratio with a 95\% confidence interval (CI) of logistic regression are reported. We conducted a two-level hierarchical Poisson regression analysis to identify factors associated with the length of delay (Model B). Prevalence ratio (PR) and adjusted prevalence ratio with a $95 \% \mathrm{CI}$ of Poisson regression are reported. A cluster effect was found at the individual level when an empty model was used (Model A: Intraclass Correlation Efficient $($ ICC $)=0.3581, p<0.0001$, Model B: ICC $=0.3452, p<0.0001)$. Variables with bivariate $p$-value $<0.10$ in univariable regression were forced into subsequent multivariable regression. All the data analyses were performed using SAS, version 9.4 (SAS Institute Inc., Cary, NC, USA).

\subsection{Ethical Statemtent}

The study protocol was reviewed and approved by the Institutional Review Board (IRB) of the School of Public Health, Sun Yat-sen University, Guangzhou, China (No: 2013-26). 


\section{Results}

\subsection{Demographics and Methadone Treatment-Related History}

From the data collected in this study, a total of 459 individuals completed 2940 transfers between 1 January 2008 and 1 December 2016. The mean age of the patients was $40.40(\mathrm{SD}=6.22)$ years old, and most of them were male $(88.45 \%)$, educated to middle school level $(80.83 \%)$, and unemployed or had a part-time job $(65.58 \%)$. The mean duration of methadone treatment was 6.80 years $(\mathrm{SD}=2.03)$. The average initiated age of drug use was $23.12(\mathrm{SD}=5.59)$ years old. Most patients had an intravenous drug use history $(88.89 \%)$, and more than half of the patients $(54.03 \%)$ had dropped out and re-enrolled in MMT (Table 1).

Table 1. Individual characteristics and methadone maintenance treatment (MMT) history (level 2).

\begin{tabular}{ll}
\hline \multicolumn{1}{c}{ Characteristics } & $n=459$ \\
\hline $\begin{array}{l}\text { Demographics } \\
\text { Sex, } n(\%)\end{array}$ & \\
$\quad$ male & $406(88.45)$ \\
$\quad$ female & $53(11.55)$ \\
Age, Mean \pm SD & $40.41 \pm 6.22$ \\
Employment status, $n(\%)$ & \\
$\quad$ unemployment or part-time job & $301(65.58)$ \\
$\quad$ full-time job & $158(34.42)$ \\
Education level, $n(\%)$ & \\
$\quad \leq$ high school & $371(80.83)$ \\
$\quad>$ high school & $88(19.17)$ \\
Drug-related history & \\
Intravenous drug use, $n$ (\%) & \\
$\quad$ yes & \\
$\quad$ no & $408(88.89)$ \\
Methadone treatment-related history & $51(11.11)$ \\
Duration of received methadone treatment (years), Mean \pm SD & \\
Dropout and then MMT re-enrollment, $n$ (\%) & $6.80 \pm 2.03$ \\
$\quad$ yes & \\
$\quad$ no & $248(54.03)$ \\
Age of initiated drug use, Mean \pm SD & $211(45.97)$ \\
No. of times of transferred, interquartile range (IQR) & $23.12 \pm 5.59$ \\
Frequency of transfer service utilization (times/year), IQR & $4.00(2.00,11.00)$ \\
\hline
\end{tabular}

\subsection{Transfer Patient Characteristics}

The frequency of patient transfers each year varied from 1 to 32 times (Median: 0.78, IQR: 0.29-2.00). The average number of days documented on a patient's application form for a transfer request to their secondary clinic was 9.00 days (IQR: 2.00-30.00). Most patients declared work as the reason for their transfer request (82.71\%). Among all records, $40.79 \%$ of patients delayed returning to their primary MMT clinic after being transferred by an average delay of 3.00 days (IQR:1.00-6.00). Of the patients, $22.96 \%$ had at least one failed urine drug test in the last three months prior to transfer, and $18.03 \%$ of patients refused to do a urine drug test before being transferred (Table 2). 
Table 2. The characteristics of each transfer (level 1).

\begin{tabular}{ll}
\hline \multicolumn{1}{c}{ Characteristic } & \multicolumn{1}{c}{$n=\mathbf{2 9 4 0}$} \\
\hline Delayed return, $n(\%)$ & $2940(100)$ \\
yes & $1199(40.79)$ \\
no & $1741(59.21)$ \\
Average length of delay, IQR & $3.00(1.00,6.00)$ \\
No. of days transferred to other MMT clinics, IQR & $9.00(2.00,30.00)$ \\
Average daily methadone dosage during transfer period (mg/day), IQR & $63.90 \pm 33.44$ \\
Compliance rate during transfer period, IQR & $0.75(0.30,1.00)$ \\
Reason for transfer, $n(\%)$ & \\
$\quad$ work & $2467(82.71)$ \\
$\quad$ travel, medical or other & $473(17.29)$ \\
Result of urine drug tests in the past three months before transfer, $n(\%)$ & \\
positive & $675(22.96)$ \\
$\quad$ negative & $1735(59.01)$ \\
refused test & $530(18.03)$ \\
Duration of MMT before transfer (year), Mean \pm SD & $6.79 \pm 2.03$ \\
\hline
\end{tabular}

\subsection{Factors Associated with Missed Doses in Delayed Return Period}

Of the 2940 transfers, 1199 (40.79\%) were categorized as delayed return. As shown in Table 3 (Model A), patients who had a poor compliance rate during the transfer period, e.g., missed doses while at a secondary clinic (adjusted OR: $0.16,95 \%$ CI: $0.13-0.21, p<0.0001$ ), had a shorter duration of methadone treatment before being transferred (adjusted OR: $0.88,95 \%$ CI: 0.81-0.95, $p=0.0017$ ), and had previously dropped out of the MMT program (adjusted OR: 1.70, 95\% CI: 1.21-2.41, $p=0.0022$ ) were more likely to delay their return after being transferred (Table 3, Model A).

\subsection{Factors Associated with the Length of Missed Doses in Delayed Return Period}

The average length of delay was 3.00 days (IQR: 1.00-6.00) among 1199 delayed transfers. Patients who frequently transferred each year (adjusted PR: 1.06, 95\% CI: 1.02-1.11, $p=0.0104$ ) and those with a dropout and re-enrollment history (adjusted PR: 1.78, 95\% CI: 1.38-2.29, $p<0.0001$ ) were more likely to extend their delayed return to their primary MMT clinic. Patients who had poor compliance rates during the transfer period (adjusted PR: $0.26,95 \%$ CI: $0.24-0.29, p=0.0037$ ), shorter duration of methadone treatment before transfer (adjusted PR: 0.89, 95\% CI: 0.84-0.95, $p=0.0032$ ), used the transfer service for work (adjusted PR: 1.20, 95\% CI: 1.07-1.35, $p=0.0099$ ), and had at least one positive urine drug test in the last three months before being transferred (adjusted PR: 1.10, 95\% CI: 1.02-1.19, $p=0.0396$ ) were more likely to extend their length of delayed return (Table 3, Model B). 
Table 3. The association between transfer service use and delayed return of transferred patients, obtained from the multilevel regression model.

\begin{tabular}{|c|c|c|c|c|}
\hline \multirow{2}{*}{ Predictors } & \multicolumn{2}{|c|}{ Model A: Return on Time or Delayed Return ${ }^{\text {a }}$} & \multicolumn{2}{|c|}{ Model B: Length of Delay ${ }^{b}$} \\
\hline & Univariable & Multivariable & Univariable & Multivariable \\
\hline \multicolumn{5}{|l|}{ Transfer service use-level variables } \\
\hline Days of each transfer to other MMT clinics & $1.00(0.99-1.00)$ & & $0.99(0.99-0.99)$ & \\
\hline Average daily methadone dosage during transfer period (mg/day) & $1.00(0.99-1.00)$ & & $0.99(0.99-1.00)$ & \\
\hline \multicolumn{5}{|l|}{ Reason for transfer } \\
\hline travel, medical or other & Ref & Ref & Ref & Ref \\
\hline work & $1.47(1.07-2.02) * *$ & $1.17(0.89-1.52)$ & $1.23(1.13-1.35) * * *$ & $1.20(1.07-1.35) * *$ \\
\hline Compliance rate during transfer period & $0.17(0.13-0.23)^{* * *}$ & $0.16(0.13-0.21)^{* * *}$ & $0.26(0.23-0.28) * * *$ & $0.26(0.24-0.29)^{* * *}$ \\
\hline Duration of MMT before transfer & $0.92(0.85-0.99) *$ & $0.88(0.81-0.95)^{* * *}$ & $0.94(0.89-0.99) *$ & $0.89(0.84-0.95)^{* * * *}$ \\
\hline \multicolumn{5}{|l|}{ Results of urine drug test in the past three months before transfer (\%) } \\
\hline negative & Ref & & Ref & Ref \\
\hline positive & $1.11(0.88-1.40)$ & & $1.15(1.06-1.24) * * *$ & $1.10(1.02-1.19) * *$ \\
\hline \multicolumn{5}{|l|}{ Individual-level variables } \\
\hline Frequency of transfer service use (times/year) & $1.05(1.00-1.11)$ & & $1.06(1.02-1.10)^{* * *}$ & $1.06(1.02-1.11)^{* *}$ \\
\hline \multicolumn{5}{|l|}{ Dropout and then MMT re-enrollment } \\
\hline no & Ref & & Ref & \\
\hline yes & $1.35(1.00-1.82) *$ & $1.70(1.21-2.41)^{* * *}$ & $1.44(1.14-1.83) * *$ & $1.78(1.38-2.29)^{* * *}$ \\
\hline Age of initiated drug use (years) & $0.99(0.97-1.02)$ & & $1.00(0.98-1.03)$ & \\
\hline \multicolumn{5}{|l|}{ Intravenous drug use, $n(\%)$} \\
\hline no & Ref & & Ref & \\
\hline yes & $1.05(0.64-1.72)$ & & $0.37(0.93-2.01)$ & \\
\hline Age & $0.99(0.96-1.01)$ & & $1.01(1.00-1.03)$ & \\
\hline \multicolumn{5}{|c|}{$1.01(1.0001 .00)$} \\
\hline female & Ref & & Ref & \\
\hline male & $0.69(0.42-1.13)$ & & $0.73(0.51-1.05)$ & \\
\hline \multicolumn{5}{|l|}{ Employment status, $n(\%)$} \\
\hline full-time job & Ref & & Ref & \\
\hline unemployed or part-time job & $1.30(0.93-1.81)$ & & $0.87(0.68-1.12)$ & \\
\hline \multicolumn{5}{|l|}{ Education level, $n(\%)$} \\
\hline >high school & Ref & & Ref & \\
\hline$\leq$ high school & $1.16(0.78-1.72)$ & & $0.95(0.71-1.28)$ & \\
\hline
\end{tabular}




\section{Discussion}

In the six MMT clinics included in our study, patients who used the transfer system regularly delayed return to their primary MMT clinic. Almost $40 \%$ of patients delayed return to their primary clinic by an average of three days. These findings are consistent with others [21] reporting that patients delayed return to their primary MMT clinic in Shenzhen by 3.55 days. According to Chinese regulations, patients cannot access MMT without the permission of their primary clinic if their transfer application expires while at a secondary clinic [13]. This regulation is said to protect patients from the risk of misuse and overdoses [11,29]. While reasonable, our research suggests that patients with a poor compliance history might be involved in a cyclical problem exacerbated by the administration system.

When a patient wants to extend their stay at their transfer destination beyond what was detailed in their transfer application form, they need to inform their primary MMT clinic. Then, the application needs to be processed and authorized by the patient's primary MMT clinic's doctor. It must also be approved by the clinic's administrative regulators. In our experience from working in a clinic, it can take between one to two days for the National MMT Data Management System to be updated. This delay might push the patient to choose illicit drug use during the missed dose period(s), which puts them and others at increased risk of social harm [30]. We suggest that the MMT administrative system needs to be more flexible, so patients can more easily extend treatment at their secondary clinic. Given the immediacy of an online system, this would appear to present few information technology (IT) challenges as long as system checks are put in place.

Research has shown that MMT patients are self-employed or have a part-time job [31,32]. Most of the patients in this study declared "work" as their reason for transfer request $(82 \%)$. This is much higher than reported in other research projects $(40-50 \%)$ [33,34]. Notably, the participants who used the transfer service for work were more likely to extend their length of delay. This suggests that patients are struggling to balance their work and clinic commitments and may need to travel for work due to limited opportunities and potentially discrimination [35]. However, the data in our study concerning employment status were self-reported and collected at the time of enrolment, so it may not be reliable as most of the patients claimed they were not employed in the audit records (Table 1). Further in-depth research is needed as to why patients transfer and why they delay return to their primary MMT clinic.

Consistent with the research on urine drug tests from MMT patients, nearly $20 \%$ of patients failed a urine drug test within three months before being transferred [36,37], which is fewer than the $46 \%$ detailed in other research [38]. Even considering the number of patients who refused a drug test $(18.03 \%)$ prior to being transferred, we are reasonable to think that transfer patients self-manage well during the transfer period.

A shorter patient MMT history and dropout and re-enrollment rate in MMT are general indicators of poor compliance with the transfer treatment. This finding is in agreement with a number of studies that have shown that patients in their early stages of treatment are more likely to contravene the clinic regulations [39-41]. Overall, delayed return is associated with the characteristics of patients and the MMT clinic transfer system. Patients with a dropout and re-enrollment history and shorter methadone treatment history were more likely miss their doses after temporary leave. We suggest changes need to be made to the administrative system to accommodate patients who transfer regularly. Our research also provides a reference for establishing a cross-regional system for MMT clinic transfer patients.

The findings of this study suggest that a few policy changes are needed. Firstly, an effective and flexible transfer management, especially the end-date of transfer, should be introduced to MMT systems to prevent delayed return. The authorities should provide convenient and quick transfer services for patients to avoid missed doses. Secondly, the coverage of MMT clinics and the comprehensive MMT services should be provided for all patients to improve participant compliance. Especially for patients with a drop-out history, we suggest closely monitoring their methadone dosage and urine drug tests to prevent the delayed return after transfer. Thirdly, for compliant participants with long-distance transfer, take-home dosage could be provided for two or three days to ensure they receive their dosage during the delay period. The take-home MMT strategy available in countries such as Israel, Singapore, and the 
United States has been effective in improving patient compliance [7,42-44]. In 2017, an innovative study on methadone take-home strategies was conducted in Yunnan, China, where the local authorities provided take-home doses for MMT patients using a high-tech internet-connected treatment box with four days' dosages $[45,46]$. Through the internet-connected box, patients took methadone remotely via the supervision of the staff while physically absent from their primary MMT clinic [46]. Though this take-home, high-tech strategy may be widespread in the future, we suspect such a roll out is unlikely anytime soon. In the meantime, we should focus on improving compliance rates among MMT patients. Of particular concern to us here is the compliance rates among those who use the transfer system.

This present study has some limitations. One, information was exacted from the electronic database, meaning other factors may potentially be correlated with the delayed return that were not collected. Therefore, a future quantitative study is needed to investigate additional details about the transfer period. Two, all subjects were selected using convenience sampling from six clinics in Guangdong, which might lead to selection bias, so we need to be cautious about generalizing the findings to all MMT patients. Future investigation among transferred patients on a larger scale is needed to determine the long-term impact of delayed return on transfer experiences. Three, compared with other provinces of China, Guangdong province has better economic development and provides more jobs, which may affect the utilization of transfer service in the MMT. In further study, the investigation of features of MMT patients in Guangdong and other areas of China is needed.

\section{Conclusions}

In our analysis of six MMT clinics in Guangdong, China, delayed return among MMT patients who used the transfer system was common. Patients with a poor compliance history appear to be involved in a cyclical problem exacerbated by the fixed administrative system. Our study highlights the characteristics of transfer patients and identifies those at high risk of delayed return: those who have enrolled multiple times, those who have a short history of MMT, and those with a history of failed urine drug tests in the three months prior to transfer. Our research outlines the need for flexibility within the MMT administrative system in China to help increase compliance rates.

Author Contributions: Conceptualization, X.Z., W.C., and L.L.; Data curation, C.G.; Investigation, Y.L. and Q.L.; Project administration, L.L.; Writing—original draft, C.G.; Writing—review \& editing, C.G., X.Z., W.C., L.L., and Q.L.

Funding: This study was funded by the National Natural Science Foundation of China (NO. 81473065).

Acknowledgments: The authors are grateful to Andre MN Renzaho and Shuxian Wu for their guidance and comments. The authors appreciate the collaboration of staff from MMT clinics and our research team, Xiaoling Huang, and Yuewen Dang for their valuable assistance in data collection, and Mr. Christopher Lavender for helping us improve our English expression.

Conflicts of Interest: The authors declare no conflict of interest.

\section{References}

1. Van Den Brink, W.; Haasen, C. Evidenced-based treatment of opioid-dependent patients. Candian J. Psychiatry 2006, 51, 635-646. [CrossRef] [PubMed]

2. McLellan, A.T.; Lewis, D.C.; O’Brien, C.P.; Kleber, H.D. Drug dependence, a chronic medical illness: Implications for treatment, insurance, and outcomes evaluation. Jama 2000, 284, 1689-1695. [CrossRef] [PubMed]

3. Grissinger, M. Keeping patients safe from methadone overdoses. Pharm. Ther. 2011, 36, 462-466.

4. Hser, Y.I.; Hoffman, V.; Grella, C.E.; Anglin, M.D. A 33-year follow-up of narcotics addicts. Arch. Gen. Psychiatry 2001, 58, 503-508. [CrossRef] [PubMed]

5. Segest, E.; Mygind, O.; Bay, H. The influence of prolonged stable methadone maintenance treatment on mortality and employment: An 8-year follow-up. Int. J. Addict. 1990, 25, 53-63. [CrossRef] [PubMed]

6. Shi, J.; Zhao, L.Y.; Epstein, D.H.; Zhao, C.; Shuai, Y.; Yan, B.; Jin, J.; Lu, L. The effect of methadone maintenance on illicit opioid use, human immunodeficiency virus and hepatitis $C$ virus infection, health 
status, employment, and criminal activity among heroin abusers during 6 months of treatment in China. J. Addict. Med. 2007, 1, 186-190. [CrossRef]

7. Guo, S.; Winslow, M.; Manning, V.; Thane, K.K. Monthly take-home methadone maintenance regime for elderly opium-dependent users in Singapore. Ann. Acad. Med. Singap. 2010, 39, 429-434. [PubMed]

8. Peles, E.; Schreiber, S.; Sason, A.; Adelson, M. Earning "take-home" privileges and long-term outcome in a methadone maintenance treatment program. J. Addict. Med. 2011, 5, 92-98. [CrossRef]

9. Pani, P.P.; Pirastu, R.; Ricci, A.; Gessa, G.L. Prohibition of take-home dosages: Negative consequences on methadone maintenance treatment. Drug Alcohol Depend. 1996, 41, 81-84. [CrossRef]

10. McGloughlin, S.; Castle, E.; Coulter, C.; Fraser, J.F. The risks of diverted take-home methadone. Aust. N. Z. J. Public Health 2010, 34, 93-94. [CrossRef]

11. Yin, W.; Hao, Y.; Sun, X.; Gong, X.; Li, F.; Li, J.; Rou, K.; Sullivan, S.G.; Wang, C.; Cao, X.; et al. Scaling up the national methadone maintenance treatment program in China: Achievements and challenges. Int. J. Epidemiol. 2010, 39, 29-37. [CrossRef] [PubMed]

12. Gerra, G.; Saenz, E.; Busse, A.; Maremmani, I.; Ciccocioppo, R.; Zaimovic, A.; Gerra, M.L.; Amore, M.; Manfredini, M.; Donnini, C.; et al. Supervised daily consumption, contingent take-home incentive and non-contingent take-home in methadone maintenance. Prog. Neuro-Psychopharmacol. Biol. Psychiatry 2011, 35, 483-489. [CrossRef] [PubMed]

13. China Food and Drug Administration. Guidelines on the Management of Methadone Maintenance Treatment in China; CFDA: Beijing, China, 2015.

14. Marjot, D.H. Drug dependence. J. R. Nav. Med. Serv. 1966, 52, 150-156. [PubMed]

15. WHO. Guidelines for the Psychosocially Assisted Pharmacological Treatment of Opioid Dependence; WHO: Geneva, Switzerland, 2009.

16. Sullivan, S.G.; Wu, Z.Y.; Rou, K.M.; Pang, L.; Luo, W.; Wang, C.H.; Cao, X.B.; Yin, W.Y.; Liu, E.W.; Mi, G.D.; et al. Who uses methadone services in China? Monitoring the world's largest methadone programm. Addiction 2015, 110, 29-39. [CrossRef]

17. The College of Physicians \& Surgeons of Manitoba. Guideline of Manitoba Methadone E Buprenorphine Maintenance; University of Manitoba: Winnipeg, MB, Canada, 2014.

18. Department of Health; Ministry of Health. Guideline on Methadone Therapy and Treatment of Drug Dependence in Myanmar; WHO: Nay Pyi Taw, Myanmar, 2012.

19. British Columbia Centre on Substance Use; Ministry of Health. Methadone Maintenance Program; Clinical Practice Guideline: Vancouver, BC, Canada, 2014.

20. WHO China Office. Reducing Harm, Preventing HIV, Saving Lives: China's Vast Methadone Maintenance Treatment Program Marks Successes Even as It Addresses Key Challenges Ahead. 2014. Available online: http://www.wpro.who.int/china/mediacentre/releases/2014/2014112702/en/ (accessed on 27 November 2014).

21. Li, C.X.; Zhang, Q.S.; Deng, X.L.; Cai, C.L.; Liu, W.H.; Chen, Y.Q. Analysis of drug compliance for transfer patients in methadone maintenance treatment. Chin. J. Drug Abus. Prev. Treat. 2009, 15, 262-264.

22. Peng, H.; Wang, D.P.; Pang, Z.T.; Ding, Y.; Lin, N. Comparative analysis for transferred patients and local patients in methadone maintenance treatment. Chin. Drug Depend. 2010, 19, 366-368.

23. Nguyen, L.H.; Nguyen, H.T.T.; Nguyen, H.L.T.; Tran, B.X.; Latkin, C.A. Adherence to methadone maintenance treatment and associated factors among patients in vietnamese mountainside areas. Subst. Abus. Treat. Prev. Policy 2017, 12, 31. [CrossRef]

24. Roux, P.; Lions, C.; Michel, L.; Cohen, J.; Mora, M.; Marcellin, F.; Spire, B.; Morel, A.; Carrieri, P.M.; Karila, L.; et al. Predictors of non-adherence to methadone maintenance treatment in opioid-dependent individuals: Implications for clinicians. Curr. Pharm. Des 2014, 20, 4097-4105. [CrossRef]

25. Shen, J.; Wang, M.; Wang, X.; Zhang, G.; Guo, J.; Li, X.; Li, J. Predictors of poor adherence to methadone maintenance treatment in Yunnan province, China. J. Addict. Med. 2016, 10, 40-45. [CrossRef]

26. Wolff, K. Characterization of methadone overdose: Clinical considerations and the scientific evidence. Ther. Drug Monit. 2002, 24, 457-470. [CrossRef]

27. China National Narcotic Control Committee. China Drug Report; China National Narcotic Control Committee: Beijing, China, 2017.

28. Chen, T.; Zhao, M. Meeting the challenges of opioid dependence in China: Experience of opioid agonist treatment. Curr. Opin. Psychiatry 2019. [CrossRef] [PubMed] 
29. Zhou, Y.; Luo, W.; Cao, X.B.; Zhang, B.; Wu, Z.Y. Overdose of heroin and influencing factors in intravenous drug users in parts of Yunnan. China J. Epidemiol. 2016, 37, 648-652. [CrossRef]

30. Fischer, B.; Chin, A.T.; Kuo, I.; Kirst, M.; Vlahov, D. Canadian illicit opiate users' views on methadone and other opiate prescription treatment: An exploratory qualitative study. Subst. Use Misuse 2002, 37, 495-522. [CrossRef] [PubMed]

31. Richardson, L.; Wood, E.; Montaner, J.; Kerr, T. Addiction treatment-related employment barriers: The impact of methadone maintenance. J. Subst. Abus. Treat. 2012, 43, 276-284. [CrossRef] [PubMed]

32. Nong, V.M.; Boggiano, V.L.; Nguyen, L.H.T.; Nguyen, C.T.; Nguyen, L.H.; Bach, T.X.; Nguyen, H.V.; Hoang, C.D.; Latkin, C.A.; Vu, M.T.T. Ability to join the workforce and work productivity among drug users under methadone maintenance treatment in a mountainous area of Northern Vietnam: A cross-sectional study. BMJ Open 2017, 7, e016153. [CrossRef] [PubMed]

33. Jiang, H.; Han, Y.; Du, J.; Wu, F.; Zhang, R.; Zhang, H.; Wang, J.; Zhou, Z.; Hser, Y.I.; Zhao, M. Factors associated with one year retention to methadone maintenance treatment program among patients with heroin dependence in China. Subst. Abus. Treat. Prev. Policy 2014, 9, 11. [CrossRef]

34. Wei, X.; Wang, L.; Wang, X.; Li, J.; Li, H.; Jia, W. A study of 6-year retention in methadone maintenance treatment among opioid-dependent patients in Xi'an. J. Addict. Med. 2013, 7, 342-348. [CrossRef]

35. Tran, B.X.; Nguyen, L.H.; Tran, T.T.; Latkin, C.A. Social and structural barriers for adherence to methadone maintenance treatment among Vietnamese opioid dependence patients. PLoS ONE 2018, 13, e0190941. [CrossRef]

36. Li, L.; Liang, L.J.; Lin, C.; Feng, N.; Wu, Z. Comparison between urinalysis results and self-reported heroin use among patients undergoing methadone maintenance treatment in china. Subst. Use Misuse 2017, 52, 1307-1314. [CrossRef]

37. Joseph, H.; Stancliff, S.; Langrod, J. Methadone maintenance treatment (MMT): A review of historical and clinical issues. Mount Sinai J. Med. 2000, 67, 347-364.

38. Sharma, V.; Chamroonswasdi, K.; Srisorrachatr, S. Rate of adherence to and factors associated with methadone maintenance treatment program (Mmtp) compliance among Injecting drug use Patients In nepal. Southeast Asian J. Trop. Med. Public Health 2016, 47, 287-298. [PubMed]

39. Huissoud, T.; Rousson, V.; Dubois-Arber, F. Methadone treatments in a swiss region, 2001-2008: A registry-based analysis. BMC Psychiatry 2012, 12, 238. [CrossRef] [PubMed]

40. He, Q.; Wang, X.R.; Xia, Y.H.; Mandel, J.S.; Chen, A.; Zhao, L.L.; Han, L.; Ling, L. New community-based Methadone maintenance treatment programs in Guangdong, China, and their impact on patient quality of life. Subst. Use Misuse 2011, 46, 749-757. [CrossRef] [PubMed]

41. Bell, J.; Burrell, T.; Indig, D.; Gilmour, S. Cycling in and out of treatment; participation in methadone treatment in NSW, 1990-2002. Drug Alcohol Depend. 2006, 81, 55-61. [CrossRef] [PubMed]

42. Stitzer, M.; Bigelow, G.; Lawrence, C.; Cohen, J.; D’Lugoff, B.; Hawthorne, J. Medication take-home as a reinforcer in a methadone maintenance program. Addict. Behav. 1977, 2, 9-14. [CrossRef]

43. Gutwinski, S.; Bald, L.K.; Heinz, A.; Muller, C.A.; Schmidt, A.K.; Wiers, C.; Bermpohl, F.; Gallinat, J. Take home maintenance medication in opiate dependence. Deutsch. Arztebl. Int. 2013, 110, 405-412. [CrossRef]

44. Stitzer, M.L.; Iguchi, M.Y.; Felch, L.J. Contingent take-home incentive: Effects on drug use of methadone maintenance patients. J. Consult. Clin. Psychol. 1992, 60, 927-934. [CrossRef]

45. Ma, Y.; Du, C.; Cai, T.; Han, Q.; Yuan, H.; Luo, T.; Ren, G.; Mburu, G.; Wang, B.; Golichenko, O.; et al. Barriers to community-based drug dependence treatment: Implications for police roles, collaborations and performance indicators. J. Int. AIDS Soc. 2016, 19, 20879. [CrossRef]

46. Baran, C. Government Officials and Global Fund Implementers from Kenya, Tanzania, and Uganda Traveled to China to Learn about Local Innovations in Methadone Maintenance. Available online: Therapy.http://aidspan.org/gfo_article/global-fund-multi-country-program-east-africaspearheads-trip-china-learn-about-harm2018 (accessed on 6 July 2018).

(C) 2019 by the authors. Licensee MDPI, Basel, Switzerland. This article is an open access article distributed under the terms and conditions of the Creative Commons Attribution (CC BY) license (http://creativecommons.org/licenses/by/4.0/). 